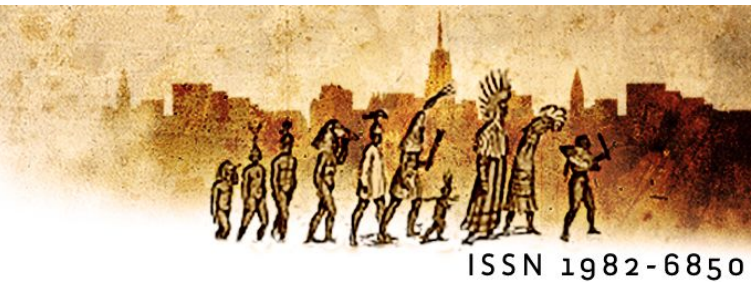

\title{
Romances e não-romances
}

Luciene Azevedoi (UFBA)

Resumo: Desde as anotações de Barthes, feitas para seu curso sobre a Preparação do Romance, até dicções mais veementes como as do ensaio-manifesto "Literatura pós-autônomas" de Josefina Ludmer, é possível ler uma drástica operação de esvaziamento sofrida pela literatura na contemporaneidade, afetando o romance como forma de ficção pura. Nesse sentido, sem negligenciar a extensa bibliografia teórica sobre o romance que não se cansa de realçar a instabilidade de sua forma como traço característico do gênero, gostaria de aproveitar esse mote e arriscar a hipótese de que alguns exemplos contemporâneos sugerem novas maneiras de fabricar e consumir literatura hoje, que apontam para a remodelação das fronteiras do gênero romanesco. Flertando com o ensaio, com a prática da anotação ou com a autoficção, os romances parecem exceder a forma do próprio romance, expondo ao leitor a manufatura do processo de composição, descartando a própria literatura como fonte da produção literária.

Palavras-chave: romance, gênero literário, não-romance.

\begin{abstract}
To someone who studies the novel form, it is striking the number of critical references commenting further transformations experienced by the genre at the beginning of the 21st century. Since the annotations made by Barthes, published as The Preparation of Novel, to more vehement pronouncements, such as the "Post-autonomous Literatures Manifesto", by Josefina Ludmer, one can see a drastic emptying operation suffered by literature in contemporary times, affecting the novel as a form of pure fiction. Thus - and without neglecting the extensive theoretical literature on the novel that never tires of emphasizing the instability of its form as a characteristic trait of the genre - I would like to take this opportunity and try out the hypothesis that some contemporary examples suggest new ways to produce and consume literature today, pointing to the remodelling of the novelistic genre's borders. Flirting with the essay, with the practice of annotation or with selffiction, some novels seem to go beyond the form of the novel itself, exposing the reader to the manufacturing of the writing process, and discarding literature itself as a source of literary production. Without yielding to the apocalyptic rhetoric and suggesting another round of the death of novel or the end of literature, the hypothesis acknowledges the novel's imprecise generic status and believes that its changing plasticity is able to reshape literary values, incorporating what still does not seem novel or fiction to the territory of literature.
\end{abstract}

Keywords: novel, literary genre, essay. 
A Revista Serrote, publicada em novembro de 2012, trazia um texto assinado por Lars Lyer, escritor e professor na Inglaterra, cuja intenção era satirizar mais uma evocação a uma suposta morte da literatura.

O tom sarcástico do manifesto começava com uma caricatura das representações mais comuns sobre escritores e sua visão da literatura como um quase reino sagrado. De antissociais e enigmáticos, os escritores deixaram de viver como deuses escondidos nas montanhas tal como faziam em um "tempo muito, muito distante", segundo Lyer, até se transformarem em verdadeiras celebridades, incorporando a lógica mercadológica não apenas para vender suas memórias, mas também para incentivar outros a se tornarem escritores.

É curioso notar na argumentação de Lyer a clara oposição entre os tempos que não voltam mais confrontados a uma derrisão contemporânea da literatura. Não é novidade para ninguém hoje a perda da relevância social do literário que já não é capaz de servir como suporte de qualquer formação de um imaginário nacional e tampouco como veículo de ideologias revolucionárias: "nenhum poema fomentará revolução, nenhum romance mudará a realidade" (2012, p.157). Mas na combativa retórica de Lyer, entendida como "um cadáver que já esfriou", ambiguamente, a literatura permanece viva seja pela "proliferação exponencial da autoria", seja pelo fato de que encarna uma espécie de "pantomima de si mesma", desvestindo-se cinicamente de suas ruínas por meio do carreirismo literário, da cooptação dos autores pelo regime mercantilista que antes combatiam, da fascinação, enfim, com a vida literária que lembra apenas fantasmaticamente o compromisso da literatura com a revolução da forma e das ideologias, ridicularizando qualquer make it new para repetir a tragédia apenas como farsa.

Assim essa permanência guarda algo de fake ou teatral, uma literatura que é uma "marionete cadáver", que destitui valores sagrados para a ideia de literatura que conservávamos até bem pouco tempo como a originalidade do produtor e do produto, já que "a ideia de obra-prima [...] faz parte do kitsch literário" (2012, p. 164) agora. Mesmo parecendo chutar um cachorro morto, Lyer resgata de sua dicção de manifesto sobre a morte da literatura autores que resistem a esse panorama, segundo o crítico, porque, paradoxalmente, abandonam a literatura por meio da literatura. Vila-Matas, Thomas Bernhard e Roberto Bolaño, por mais esdrúxulo que possa parecer o trio da resistência, são apontados por Lyer como exemplos concretos de que a literatura sobrevive. É o caso do 
impasse vivido pelo personagem Montano do livro de Vila-Matas que doente de literatura, perseguido por "um sistema de metáforas e associações literárias", representa a esperança de que a literatura respire em sobrevida. A ironia de Bernhard, explorando "os ressentimentos e as frustrações da pretensa vida intelectual", faz de seus narradores fracassados a forma de expressão simétrica das imposturas da vida literária contemporânea. E Os detetives Selvagens de Bolaño ao juntar dois ideais perdidos, a vanguarda e a revolução, cumpre o destino da literatura no início do novo milênio: "confrontar seu próprio fim e sobreviver". Escrevendo o epílogo de uma certa ideia de literatura, os três autores encarnam, na dicção do crítico, vingativas erínias que mantêm a possibilidade de a literatura continuar no século XXI.

O que soa como uma dialética hegeliana mal ajambrada (não só pela defesa de que a "literatura deve admitir o próprio fim de uma vez", mas pela retórica salvacionista que lança mão de palavras como "esperança" ou "despertar") poderia desencorajar aquele que vê no texto de Lars Lyer a possibilidade de especular sobre as formas literárias do presente. No entanto, são as sugestões que encerram o manifesto que mais chamam a atenção. Aí o crítico defende que se há possibilidade de que exista uma literatura depois da literatura, ela está alicerçada em uma "clareza não literária", própria do estilo do livro de Bolaño, "notavelmente não literário". Por isso, mesmo sem compartilhar as posições que motivaram a intervenção crítica de Lyer, me interessa a ideia da literatura como objeto desaparecido, quase fantasmático, que para mim evoca a ideia de um deslizamento, de uma transformação do objeto literário na direção de algo ainda não bem definido, "uma literatura que vem após a literatura", como afirma Lyer.

Mais curiosa ainda torna-se para mim essa imagem porque ela parece criar uma relação sub-reptícia com o texto da crítica argentina Josefina Ludmer que vem gerando muita discussão e que se chama "Literatura pós-autônomas". Aí, Ludmer afirma o desejo de mapear "territórios do presente" por meio de "escrituras atuais da realidade cotidiana". Elencando uma série de narrativas escritas na primeira década do século XXI na Argentina, a autora afirma que os livros são uma "prova de presente" que deslocam a pauta da leitura da prática historicista ou do registro meramente realista para a da apresentação do presente através do testemunho. Mas a colocação mais polêmica vem logo a seguir: Ludmer afirma que esses textos "não admitem leituras literárias", e não impõem ao crítico-leitor a decisão sobre se são realidade ou ficção, se são ou não literatura, pois, segundo a autora, a grande 
força dos relatos está na capacidade de fabricar o presente.

E há mais. Como uma espécie de coda, Ludmer afirma que nessas narrativas a literatura parece em fuga, ocupando um lugar fronteiriço, entre o dentro e o fora, já que ao mesmo tempo em que seu funcionamento parece obedecer às normas do regime autônomo do surgimento do literário, algo também parece contrariar essas mesmas normas, o que gera uma sensação de "êxodo", responsável por inscrever as narrativas em uma "posição diaspórica". Assim os textos continuam sendo classificados com os rótulos de gêneros literários tradicionais, muitos aparecem na ficha catalográfica classificados como 'romances', mas não parecem romances. As narrativas estão formatadas no suporte livro e trazem na capa da publicação o nome do autor, mas algo no regime de leitura parece impor um entrave ao comentário que resgate as engrenagens fundamentais ao funcionamento do literário, tal como delineado desde o século XVIII. Os "critérios ou categorias literárias como autor, obra, estilo, escritura, texto e sentido", diz Ludmer, esvaziam essa "literatura" ou qualquer comentário feito em seu nome porque parecem insuficientes como parâmetros de leitura, por mais ambíguo que isso possa parecer já que as narrativas surgem ainda reivindicando um lugar no campo literário, usando a etiqueta "literatura". Essa ambivalência, segundo a crítica argentina, está diretamente relacionada a uma outra anotação surpreendente no texto: o fato de que essas escrituras abrem mão da metáfora, inscrevendo-se fora da literatura e do regime ficcional, puramente imaginário, associado ao regime discursivo da literatura há séculos.

A investida mais arrojada de Ludmer nesse texto, que, curiosamente, também assume ares de um manifesto, é a afirmação de que estaríamos experimentando o fim da era da autonomia literária iniciada por Kant e que funcionou como marco inicial da modernidade estética. As evidências mais imediatas disso seriam não apenas a perda do poder crucial que a literatura experimentou ao longo do século $X X$, mas a inequívoca insuficiência da autorreferencialidade, que, se já foi considerada a espinha dorsal de grandes obras literárias daquele século, hoje, segundo Ludmer, não pode ser encarada como um valor de qualidade literária. Aqui, as semelhanças da elaboração do argumento com as proposições de Lyer parecem incontornáveis. Ou seja, continuar a falar de dentro da literatura, ou em seu nome (que nos termos de Lyer implicaria restaurar a originalidade criativa do autor, o incansável investimento formal visando à composição da obra-prima e a opção pelo princípio ético da mudança das realidades sociais através do discurso literário), 
significa ressuscitar um morto que só pode funcionar no teatro fake da contemporaneidade como uma "marionete cadáver". Como resistência a esse final indigno, resta à literatura se reinventar não-literariamente, deixando para trás uma herança que estava sendo vilipendiada por oportunistas.

Se a dicção de Ludmer não é tão dramática assim, seu argumento indica conclusão semelhante, pois ao afirmar que "as relações especulares, o livro no livro, o narrador como escritor e leitor, as duplicações internas, recursividades, isomorfismos, paralelismos, paradoxos, citações e referências a autores e leituras" ainda estão presentes como marcas do literário e pagam tributo à literatura autônoma, situando-se "simbolicamente dentro da literatura", está afirmando também que há um conjunto de critérios e valores que, embora julgados por Ludmer como insuficientes permanecem vivos ainda hoje quando evoca-se a palavra literatura. No entanto, Ludmer não deixa de notar que esses textos são confrontados com outros que optam pelo lixo e indicam a formação de um novo imaginário de entendimento. Sem esclarecer devidamente como funcionam as narrativas dessa última categoria, podemos inferir que esses textos mudam o estatuto da literatura, aparecem em "outra episteme", pedem outros modos de leitura.

O que me interessa capturar dos dois textos acima comentados é que, embora ambos pareçam partir de horizontes epistemológicos de compreensão da literatura muito distintos entre si, indicam uma desestabilização do modo de compreensão desse objeto no século XXI. Nesse sentido, são eles próprios indícios de uma mudança por se constituírem casos exemplares da discussão em torno do estatuto do literário no contemporâneo, para além das propostas que fazem sobre um possível modo de entendimento da literatura hoje.

Embora não seja nosso objetivo realizar o mapeamento dos textos que problematizam essa questão, na minha cartografia de leituras não é possível deixar de fora a evocação a um texto de Roland Barthes, que a mim mesma soa quase extemporâneo, já que o texto a que me refiro são as anotações feitas pelo próprio Barthes como preparação ao último curso ministrado por ele no Collège de France em 1984. Refiro-me especificamente à parte final dessas anotações quando Barthes em um curso sobre o romance pede desculpas aos ouvintes por ter fracassado ele mesmo na elaboração de sua ficção, já que o "fim material do Curso deveria coincidir com a publicação real da Obra, cujo encaminhamento e vontade acompanhamos, em nível de projeto" (2005, vol. II, p. 348). A declaração de fracasso é acompanhada ainda da suspeita quase definitiva de que a obra não 
seria jamais escrita. Um parênteses ao texto acrescenta que a decisão pode ser atribuída à experiência do luto pela morte de sua mãe, vivido ao longo dos dois últimos anos que coincidiram com o período do curso sobre a preparação do romance. O que temos, o que restou para nós, leitores, é então não apenas a compilação das notas que orientaram as aulas, mas o próprio diário do luto. Um diário que se confunde com um rascunho, que, assim como as anotações para a aula, podem servir de preparação para uma obra: "Quem sabe? Talvez um pouco de ouro nestas notas?", lemos na entrada ao diário no dia 27 de outubro (2009, p. 15). A leitura dos dois volumes de A preparação do romance e do Diário de Luto permite-nos acompanhar dois modos diferentes de preparação: uma que anota com diligência diferentes modos de preparação para a escrita e analisa os espaços de trabalho de escritores (a casa, o quarto, a mesa de trabalho) que constituem as afinidades eletivas de Barthes. É assim que vemos anotada pelo crítico sua surpresa diante de condições de escrita tão díspares quanto as de Flaubert e Proust, o que segundo Barthes, é significativo para a construção de suas vozes literárias ${ }^{1}$. Um outro modo de funcionamento da anotação, aparece no diário. Aí, a escrita aparece marcada pela desimportância, autorizada pelo gênero de escrita ("Ao tomar estas notas, confio-me à banalidade que existe em mim" 2009, p.25) que parece conjurar uma tensão entre o literário e o não-literário, o diário e a literatura. Lidando sempre com a ambiguidade de manter um diário de luto, evitando a dramatização excessiva do sofrimento, o texto emerge como um laboratório de escrita, de cura apotropaica: "Desde a morte de mam. Deixei de ter vontade de 'construir' -excepto na escrita" (2009, p.235).

Mas o aspecto que mais me interessa realçar é a tensão subliminar entre o que ainda não é, não tem valor literário, mas pode ser incorporado como literatura: "Não quero falar disto com medo de fazer literatura - ou sem a ter a certeza de que não o será - embora de facto a literatura tenha origem nestas verdades" (2009, p.31). Entre vida e literatura, entre notas de preparação de um curso ou anotações pessoais sobre a experiência do luto e a literatura, entre a preparação e a obra, parece haver um interstício que redesenha a fronteira: dentro e fora da literatura, objeto notavelmente (não) literário.

Assim o que parece interditado como obra (a ficção, o romance) e assinalado como

\footnotetext{
1 Enquanto Flaubert julga essencial "cinco ou seis horas de tranquilidade em meu quarto, um fogo vivo no inverno e duas velas, cada noite, para me iluminar" (2005, vol.Il, p.219), Proust "durante a fabricação furiosa da Obra[...] mantém a janela sempre fechada sobre os batentes hermeticamente cerrados, cortinas puxadas".
} 
fracasso pelo próprio Barthes na última sessão de suas notas ao curso sobre a preparação do romance emerge de outra forma, sob outro valor através das próprias anotações à preparação do curso e do exercício da purgação do luto construído em paralelo biográfico pelo diário. Ambos remanejam "profunda e obscuramente" (2005, II, p.349) o que aparece sob o signo do literário.

Com isso não estou querendo afirmar que podemos ler os textos de Barthes como romances, mas que, em especial, nessas duas últimas composições aparecem indícios também de uma modificação do entendimento da literatura. Como não conclui o curso com a apresentação do romance que gostaria de escrever, Barthes escreve, para terminar, "uma espécie de perfil de Obra" que desejaria escrever ou que gostaria que alguém escrevesse para que ele pudesse ler com satisfação. A explanação é breve, mas não menos surpreendente: essa obra deve ser simples. Para tanto deve procurar a legibilidade, renunciar à metalinguagem e ao hermetismo. As prerrogativas dessa obra em seu grau zero, que tem como principal característica a rejeição à autorreferencialidade que condena a literatura moderna ao "discurso da obra sobre a obra", nas palavras de Barthes (2005, II, p.352), parecem muito semelhantes ao conselho de Lyer aos jovens escritores para que honrem a literatura escrevendo com "clareza literária" ou mesmo às injunções de Ludmer ao prever uma desmetaforização da literatura pós-autônoma. Se a posição do precursor nega ao contemporâneo qualquer dicção de "extenuação trágica da literatura" (2005, II, p. 352), é notável a lucidez da avaliação sobre o próprio recorte que efetua. Consciente de que trabalha ao longo das aulas do curso com referências da alta modernidade (Flaubert, Mallarmé, Kafka, Proust), Barthes afirma que as obras contemporâneas são colocadas entre parênteses por um desejo que retorna sempre ao passado e se desvia e "ignora mil trabalhos atuais" (2005, II, p.359), mas que, no entanto, espera um "clique", "uma nova escuta das coisas", asseverando que a "Obra Nova" [...] só é possível, só pode realmente deslanchar quando um gosto antigo é transformado, e um gosto novo aparece" (2005, II, p.360).

Reconhecendo uma certa cegueira para o contemporâneo, Barthes no entanto não ignora a possibilidade de um novo tipo de obra. Desde suas anotações feitas para seu curso sobre a preparação do romance, até dicções mais veementes como as do ensaio-manifesto "Literatura pós-autônomas" de Josefina Ludmer, é possível ler uma drástica operação de esvaziamento sofrida pela literatura na contemporaneidade, afetando o romance como 
forma de ficção pura. Considerando nossa atualidade seria possível considerar que os textos de Lyer e Ludmer provam que estamos mais atentos para a escuta do 'clique' de um novo objeto literário?

Não se trata de eleger o novo como imprescindível ou marca absoluta de uma alteração da noção do literário, já que a própria ideia de novidade parece manter todas as coisas em seus lugares modernos, se nos lembramos da já clássica noção de "tradição da ruptura" do velho Octavio Paz. Mas talvez valesse a pena ouvir esse 'clique', testar a hipótese de que a literatura tem se arriscado na direção de uma saída da ficção, enfrentando-se a um estado de precariedade, de simplicidade, que torna difícil a composição de uma forma, entendida nos termos modernos como uma "unidade estrutural que imita um mundo", segundo Bourriaud (2009), e que por isso faz vacilar seu próprio estatuto.

A extensa bibliografia teórica sobre o romance não se cansa de realçar a instabilidade da forma como traço característico do gênero, assinalando sua capacidade de autoparodização sistemática, que implica em um travestimento narrativo (cf. BAKHTIN, 1988) que dá ao gênero um caráter inacabado, informe, resultando em uma remodelação das fronteiras do que chamamos de romance. Também não passa despercebido a qualquer estudioso do gênero que as obras literárias do século $X X$ trabalharam para matar o romanesco do romance, na tentativa de "reorganizar-lhe a forma em linhas menos narrativas' (GOODY, 2009, p. 63), investindo pesado na inventividade formal. Dessa forma, talvez fosse possível pensar uma continuidade do romance no contemporâneo que, por um lado, o mantivesse fiel à sua tradição de forma inacabada e, por outro, reconhece nas obras da atualidade um certo cansaço com a forma experimental do relato. $\mathrm{O}$ abandono da forma, da autorreferencialidade, da metaforização, marcas estéticas das obras literárias de boa parte da produção literária do século $X X$, representaria, portanto, simultaneamente, uma continuidade e uma ruptura para o romance. Escrever com simplicidade, como postulava Barthes, privilegiando a clareza literária (como diria Lyer), significaria, portanto, manter a tradição teórica que reconhece que "o romance só pode chegar a uma nova maestria quando perde passageiramente o leme e o rigor" (SANTIAGO, 1989, p.29), afastando-se do porto seguro das fórmulas estéticas da alta modernidade e assumindo o risco da nãoliteratura, do não-romance.

Por se manterem fiéis à plasticidade do gênero essas formas podem ser 
"diaspóricas", para retomar a expressão utilizada por Ludmer, mantendo-se ao mesmo tempo dentro e fora da própria literatura, termo elástico por excelência ${ }^{2}$. Dessa forma, a negatividade dos não-romances indicaria apenas a indefinição, a ambiguidade de seu lugar em mais uma remodelação do gênero.

Gostaria, portanto, de aproveitar esse mote e arriscar a hipótese de que alguns exemplos contemporâneos sugerem novas maneiras de fabricar e consumir literatura hoje. Flertando com o ensaio, com a prática da anotação ou com a autoficção, os romances parecem exceder a forma do próprio romance ${ }^{3}$, expondo ao leitor a manufatura do processo de composição, a possibilidade de explorar o relato do trabalho com a manufatura da obra, revelando os andaimes da escrita e apostando na "potencia de los procesos contingentes y estructuralmente inconclusos... (e menos no) valor estético de sus resultados" (GIORDANO, 2011, p.89).

Sendo assim, o livro de Ivan Vladislavic, The Loss Library and Other Unfinished Stories, pode servir como um bom estudo de caso ${ }^{4}$. Vladislavic é um escritor sul-africano de origem croata que se lançou à ficção em 1989. Seu nome está longe de obter o reconhecimento mundial de seu compatriota, John Coetzee, mas se a proliferação das traduções das obras do vencedor do prêmio Nobel pode ser considerada um elemento inibidor da circulação do nome de Vladislavic em circuitos literários mais amplos, parece inegável também que nossa república mundial das letras, motivada pela descoberta de Coetzee, ampliou seu interesse para a produção literária sul-africana e talvez, graças a isso, seja possível ler hoje edições inglesas das obras do autor.

As publicações de Vladislavic parecem ter se aprimorado em problematizar a própria fronteira do gênero literário em que se inscrevem. Além do diálogo com a imagem, presente em seu último romance $A$ Labour of Moles (2012), e que tem se firmado como uma marca da assinatura do escritor, The Exploded view (2004) apresentava ao leitor a possibilidade de ler o que parecia a reunião de quatro narrativas como um romance em quatro partes. Mas o texto que parece um divisor de águas na carreira de Vladislavic,

2 Aproprio-me do termo tal como utilizado por Luiz Costa Lima para sugerir a expansão do território da literatura. cf. História. Ficção. Literatura. S.P. Cia das Letras, 2006.

3 Outros textos escritos por mim têm tentado aprofundar essa reflexão: "Quanto vale a escrita de si?", publicado em Ética e Estética nos Estudos Literários, In: WEINHARDT, M. [et al.] orgs. Curitiba/PR, Editora UFPR, 2013 e "O romance e a anotação", publicado na revista Contexto/Ufes, 2013.

4 Agradeço a Antonio Marcos Pereira a indicação do autor, do livro e da resenha à publicação escrita por Hedley Twidle e disponível em http://publicbooks.org/fiction/dont-say-etc 
alçando-lhe a uma certa projeção mundial, é Portrait with Keys (2006), uma espécie de diário de anotações do próprio autor sobre suas impressões sobre Johannesburgo. Se não paira dúvida sobre o status não ficcional dessa série de pequenos fragmentos que comentam o cotidiano da cidade pela perspectiva do observador atento que arquiva seu olhar por meio da escrita, o mesmo não pode ser dito The Loss Library, publicado em 2012 e que será objeto de análise mais detalhada a partir de agora.

O livro é um conjunto de relatos sobre histórias que fracassaram narrativamente, nunca chegaram a ser escritas e são resgatadas, recicladas por Vladislavic que, generosamente, compartilha com o leitor seu processo de descarte, o 'lixo' de sua produção: "histórias que imaginei, mas que não pude escrever, ou comecei a escrever, mas não terminei" (2012, p.1). Os textos coligidos no livro são tratados pelo autor como "estudos de caso" porque interessam também como especulação para explicar, tornar mais clara, não apenas a motivação para manter as ideias anotadas em caderninhos durante longo período (quase 20 anos), mas principalmente para entender 0 fato de que permaneceram incompletas todo esse tempo. Antes mesmo de começarmos a ler cada uma das narrativas nos deparamos com uma espécie de mote que traz o resumo do argumento associado a uma data. Não ficamos sabendo ao certo se se trata da ideia originalmente anotada para o posterior desenvolvimento narrativo. Da mesma maneira que não sabemos se as entradas que aparecem ao final das histórias, e que trazem reflexões sobre a impossibilidade de escrevê-las, são mesmo diretamente retiradas dos cadernos de anotação do escritor, pois embora apareçam datadas ("Notebook, Oct, 1992", p. 13) parecem sofrer interpolações, acréscimos, desenvolvimento com a retomada para a publicação que conta a história do fracasso.

A primeira narrativa do livro ("The Last Walk") sobre uma história que não foi escrita tem como mote "o escritor em sua última caminhada, um passeio solitário pela paisagem de inverno" (2012, p.9) e que evoca imediatamente no leitor as circunstâncias da morte de Robert Walser. Quando começamos a ler o que efetivamente é a história da não-história, o relato da narrativa que não chegou a se tornar literária, acompanhamos primeiro uma breve apresentação de Walser, seguida das reflexões que a famosa foto do escritor morto na neve provoca em Vladislavic: o fato de que até aquele momento não tinha lido nenhuma obra de Walser, o chapéu do escritor, caído próximo a seu corpo, a surpresa pelo fato de a foto mostrar a neve intacta ao redor do corpo do escritor, como se ninguém houvesse se 
aproximado sequer para confirmar sua morte, o punctum representado pela marca das leves pegadas em círculo, que parecem revelar a perda do equilíbrio antes da queda. Aos leitores é revelado, então, uma espécie de passeio mental efetuado pelo narrador que cultiva a ideia de escrever sobre os últimos dias de um escritor. Mas, surpreendentemente, para os leitores e para o próprio Vladislavic, a história é interditada porque o escritor diz estar preocupado com chapéus (2012, p.9). Passamos então, como se também fôssemos convidados a passear, às observações feitas sobre outra foto. A imagem de 1941 descrita no texto registra o enforcamento de iugoslavos capturados por soldados alemães na tomada de Pancevo, durante o nazismo. Vladislavic relata o incômodo causado pela aparente calma dos espectadores diante de uma cena de horror, mas sua atenção termina desviada pela "expressão tranquila de um homem jovem usando óculos e chapéu" $(2012$, p.9) que dispara a inquietação pelo inusitado da presença do complemento em um enforcado: "Por que ele está usando chapéu nessas circunstâncias extremas?" (2012, p.11). Sem encontrar respostas às perguntas que faz, a elucubração deriva para a lembrança de uma passagem do livro de Geoff Dyer, $O$ Instante Contínuo, em que pode ler a história do chapéu através da fotografia americana dos anos 30: "antes da Depressão, o chapéu era um sinal de otimismo, de prosperidade; depois tornou-se uma marca de pobreza, de desafiadora resistência" (2009, p.12).

"O que aconteceu à história sobre o escritor no dia seguinte à sua morte?"(2012, p.13), estupefação do leitor que é refletida pela pergunta que figura no caderno de anotações de Vladislavic. O autor chega à conclusão de que Walser não é o objeto principal de sua história e que por esse motivo não pode terminá-la, já que é incapaz de abrir mão da cronologia, insistindo em contrariar a lógica da fotografia. Se é verdade que as narrativas do século XX se esmeraram em contrariar a temporalidade narrativa dos romanções do século XIX, nem por isso o tempo deixou de ser a estrutura básica para a construção de um enredo, mas insistindo na cronologia da obra (no relato dos dias após a morte do escritor) que acaba por nunca ser escrita, não estaria Vladislavic sugerindo uma outra lógica de construção para as histórias?

Mas há mais: o autor diz que procura na internet a foto de Walser morto e consegue ver uma tomada da mesma imagem em ângulo reverso, o que provoca nele arrependimento pela pesquisa, pois todas as dúvidas, os mistérios acabam se dissipando: o novo ângulo mostra o chapéu de Walser mais longe de sua mão do que a impressão provocada pela visão 
da primeira foto, a neve a seu redor aparece toda pisoteada: "fui enganado por aquela pequena, indistinta imagem" (2012, p. 14). Mas a consulta à internet rende-lhe outras informações e Vladislavic acaba descobrindo que Coetzee escreveu um ensaio sobre Walser que se tornou muito popular e que alguém fez uma série de pinturas sobre a fotos de Walser morto, mas a internet é uma rede e junto às informações sobre Walser, aparecem outros interesses e nosso autor parece se deixar seduzir, perdendo-se em curiosidades, links mal amarrados, desvio, dispersão e deriva: "as informações pulam do monitor, enterrando minhas mãos no teclado" (2012, p.14). Assim termina a história.

A aparente desconexão entre Walser, chapéus, fotografia e pesquisa no google encontra um mínimo fio narrativo na montagem de anotações que recuperam histórias extraviadas, e deixam a descoberto o processo de criação do escritor, que reelabora diante do leitor, histórias sobre as não-histórias: "Você está me acompanhando?" (2012, p.52), diz o autor em "Frieze" depois de desenrolar para o leitor os inúmeros desdobramentos de uma história que permanece, entre notas, uma história não escrita.

Não deixa de causar surpresa o fato de que muitas resenhas ao livro considerem-no sem hesitar um livro de não-ficção. Não é possível identificar aí propriamente nada do que nos acostumamos a ler como literário, se consideramos a tradição da alta modernidade 5 . Encontramos, sim, o que parece um deslizamento da lógica de composição de um artefato, de um produto para a lógica de demonstração do processo de composição efetuado por meio de uma performance ensaística que coloca o próprio autor como uma espécie de editor de sua própria obra, atuando como curador de sua ficção não escrita, fazendo de sua biblioteca perdida uma espécie de laboratório que maneja o incompleto e o inacabado como matérias-primas, lidando com a manufatura da obra, privilegiando os detalhes incidentais e vertiginosos do que não foi escrito, mas permanece como vestígio.

Lendo a biblioteca perdida podemos também acompanhar a preparação de uma voz autoral, já que parte das histórias está baseada em anotações de caderninhos que datam de 1989, muito antes portanto, do lançamento do primeiro livro do autor, Missing Persons, publicado em 1993. Logo, podemos dizer também que lemos uma espécie estranha de biografia do autor e da própria obra perdida, pois a proliferação das histórias sobre as

5 Para que não pareça muito arbitrário o comentário sobre Vladislavic, aposto ainda que experiências semelhantes podem ser encontradas em Mario Levrero e sua Novela Luminosa, nos livros de David Markson, em Evan-Lavender-Smith e seu From Old Notebooks ou ainda em Every day is for the thief de Teju Cole. 
histórias que não foram escritas compõe uma espécie de edição crítica da vida e obra de um escritor por ele mesmo.

A facilidade que encontramos para descrever as histórias do livro indicam a clareza e a simplicidade da linguagem. As referências, literárias ou não, estão todas identificadas, mesmo as mais evidentes, como é o caso da história que dá título ao livro e é uma alusão clara à biblioteca borgeana, autor que aparece como personagem. Tanto no que parece uma espécie de prefácio, quanto num texto à maneira de posfácio, Vladislavic refere-se ao que lemos como anotações. A estranheza da dicção das histórias parece exacerbada pelo aparato paratextual não muito comum em textos literários (ao final do volume nos deparamos com um conjunto de notas que comentam e identificam referências surgidas nos textos e também com a indicação de fontes bibliográficas utilizadas nas histórias) e que leva o leitor a se perguntar se o que está lendo é um tipo de "não-ficção criativa" (?), uma investigação autobiográfica sobre velhos caderninhos de anotações ou um inventário de histórias que um escritor não conseguiu escrever (JAKUBOWSKI, 2012). Ficção ou não ficção? O próprio autor parece relevar a importância da pergunta.

Em "Mouse Drawing" ficamos sabendo que um incidente curioso e banal, que intriga o autor (as marcas deixadas pelo mouse de seu computador na madeira de sua mesa, depois de um dia inteiro de trabalho), rende efetivamente uma história, com a qual o autor não parece muito satisfeito, afinal. Por isso a ideia aparece retomada como uma outra história que não pôde terminar: "Talvez vocês desconfiem que a ficção foi mais elaborada, mas é menos satisfatória que o relato factual que estou dando a vocês agora. E esse relato só é possível porque a ficção não deu em nada, assim como tinha surgido do nada, por acaso." (2012, p.85-6)

As histórias que permanecem como possibilidade criam uma tensão entre o escrito e o não-escrito, o literário e o não-literário, entre a autobiografia e a ficção e parecem resgatadas de seu "estado de estúdio" (LADDAGA, 2010, p.10), para que atuem de forma precária, inacabada, num conjunto que reúne informações, ficções, documentos, referências, fotografias, invenções e projetam o autor atuando na própria obra, não apenas como personagem, mas também como curador do que apresenta para o leitor: o vestígio do que poderia ser uma boa história, a anotação de uma ideia, o refugo que foi descartado.

Em "Dr. T.", Vladislavic confessa sua pulsão arquivística não apenas em relação a suas próprias anotações, mas também como responsável pelo espólio de amigos que o elegem 
como depositário de seus papéis. Dizendo-se incapaz de recusar ou devolver os materiais que recebe, afirma que desenvolveu com os arquivos de Dr. T, de quem imaginava redigir uma biografia, uma relação especial, tratando cada um dos objetos recebidos como interessantes e valiosos em si mesmos (2012, p.98). Talvez o livro que lemos seja uma pequena mostra de um repositório de histórias não-escritas, que reconhecidas pelo próprio escritor como lixo, conservam, no entanto, a potência do não-escrito, "que bem pode ser a chave para completar a tarefa" (2012, p.98).

Em "A posição do narrador no romance contemporâneo", Adorno afirma categoricamente a impossibilidade de narrar, defende a problematização da linguagem, identifica e condena a disseminação de uma subliteratura biográfica e recomenda que o narrador assuma a posição de levar o leitor aos bastidores, à casa de máquinas do romance contemporâneo, desmascarando um realismo ineficaz para o enfrentamento com um mundo administrado, pela estandardização e pela mesmice.

Por mais que as motivações do dictum adorniano estejam ancoradas historicamente, não podemos negar que sua cartilha continua válida como parâmetro crítico de valor sobre a literatura. Nesse sentido, então, a valorização dos bastidores da escrita, nos termos que a comentamos, a exploração da performance do escritor em seu estúdio de trabalho, entendidas como dispositivos presentes nas narrativas contemporâneas só poderiam estar localizadas fora da literatura.

Mas não será possível se perguntar, então, se narrativas como as de Vladislavic que abraçam o inacabado, escolhendo contar o processo de construção, dando como suficiente a anotação de escrita, o relato de seus impasses, podem sugerir "uma nova escuta das coisas", como propunha Barthes, provocando o aparecimento de um "gosto novo", sem que isso signifique a impugnação do estatuto do literário? 


\section{Referências Bibliográficas}

ADORNO, Theodor W. "Posição do Narrador no Romance Contemporâneo". Trad.: Jorge de Almeida. In: Notas de literatura I. São Paulo: Duas Cidades, Editora 34, 2003. p. 55-63.

BAKTHIN, M. Questões de Literatura e de Estética. (A Teoria do Romance).São Paulo. Hucitec/Unesp, 1988.

BARTHES, R. A Preparação do Romance. volume II. A obra como vontade. Trad. Leyla Perrone Moisés São Paulo: Martins Fontes, 2005.

. Diário de Luto. Fixação do texto e notas Nathalie Léger. Portugal. Ed.70, 2009.

BOURRIAUD, Nicolas. Estética Relacional. S.P. Martins Fontes, 2009.

GIORDANO, Alberto. Vida y Obra. Otra vuelta al giro autobiográfico. 1ed. Rosario. Beatriz Viterbo Editora, 2011.

GOODY, Jack. "Da Oralidade à escrita. Reflexões antropológicas sobre o ato de narrar." In: Moretti, Franco (org.). A cultura do romance. Trad. Denise Bottmann. São Paulo, Cosac Naify, 2009

JAKUBOWSKI, Matthew. "The Loss Library: Ivan Vladislavic revisits his failures". Publicada em 12 de maio de 2012, disponível em http://www.thenational.ae/arts-culture/books/theloss-library-ivan-vladislavic-revisits-his-failures\#full

LADDAGA, R. Estética de laboratorio. Estrategias de las artes del presente. Buenos Aires. Adriana Hidalgo, 2010.

LYER, Lars. "Nu na banheira, encarando o abismo (um manifesto sobre o fim da literatura e dos manifestos)". Revista Serrote. Número 12, novembro de 2012.

LUDMER, Josefina. "Literatura pós-autônoma". Revista Sopro. Número 20, janeiro de 2010. Disponível em http://culturaebarbarie.org/sopro/n2o.pdf

SANTIAGO, Silviano. "Prosa Literária Atual no Brasil", in : Nas Malhas da Letra. São Paulo, Companhia das Letras, 1989.

VLADISLAVIC, Ivan. The Loss Library and Other Unfinished Stories. Seagull Books, 2012.

\footnotetext{
i Luciene AZEVEDO. Professora da Universidade Federal da Bahia (UFBA).

E-mail: lucieneazevedo@ig.com.br
} 